\title{
SUCESSÃO DE CULTIVO DE FEIJÃO-ARROZ COM DOSES DE ADUBAÇÃO NITROGENADA APÓS ADUBAÇÃO VERDE, EM SEMEADURA DIRETA ${ }^{(1)}$
}

\author{
LUCIANO BORDIN ${ }^{(2)}$; ROGÉRIO FARINELLI ${ }^{(3,5)}$; FERNANDO GUIDO \\ PENARIOL ${ }^{(3,5)}$; DOMINGOS FORNASIERI FILHO ${ }^{(4)}$
}

\begin{abstract}
RESUMO
O trabalho objetivou avaliar a viabilidade agronômica do cultivo de feijão bravo do Ceará (Canavalia brasiliensis), Crotalaria juncea cv IAC-KR1, milheto cv. BN-2 (Pennisetum glaucum), sorgo cv. AG-2501C e sorgo guiné (Sorghum bicolor tipo guinea), semeados no período de safrinha, em comparação com a área mantida no limpo. Após a dessecação, efetuada aos 70 dias de semeadura e posterior manejo dos adubos verdes, foram cultivados em semeadura direta, o feijoeiro de inverno e em sucessão, o arroz de terras altas, ambos associados às adubações nitrogenadas de 0, 25, 50 e $75 \mathrm{~kg}^{-h^{-1}} \mathrm{de} \mathrm{N}$. Concluiu-se que as gramíneas possibilitaram maior produção de matéria seca e cobertura de solo. Com relação à cultura do feijão, a maior produtividade de grãos e componentes da produção foram obtidos nos tratamentos com leguminosas e doses de 50 e $75 \mathrm{~kg} \cdot \mathrm{ha}^{-1}$ de N. A C. juncea e a C. brasiliensis influenciaram positivamente na produtividade de arroz, juntamente com doses de 50 e $75 \mathrm{~kg}$.ha- ${ }^{-1}$ de N. Dentre as gramíneas, a sucessão com o milheto foi a que proporcionou maiores produtividades para o feijão e o arroz. A utilização dos sorgos AG-2501C e guiné ocasionaram diminuição dos componentes da produção e da produtividade de arroz.
\end{abstract}

Palavras chaves: Phaseolus vulgaris L., Oryza sativa L., matéria seca, componentes da produção, rotação de culturas.

\section{ABSTRACT \\ DOUBLE CROP - COMMOM BEAN WITH UPLAND RICE, SUBMITTED TO RATES OF NITROGEN FERTILIZATION AFTER GREEN COVER UNDER NO-TILLAGE SYSTEM}

A field trial was set up aiming to evaluate the effects of green cover and nitrogen fertilization on the sequential crops: common bean during the winter and upland rice during the summer. The experiment was arranged in split-plot experimental design with four replications. The main plots were green cover species (Canavalia brasiliensis, Crotalaria juncea cv. IAC-KR1, Pennisetum glaucum cv. BN-2, Sorghum bicolor cv. AG-2501C and Sorghum bicolor guinea), and a control plot kept weed free. These plants were sowed in March and mowed in May. The sub-plot were nitrogen rates as cover fertilization $(0,25,50$ and $75 \mathrm{~kg}$.ha ${ }^{1}$ of N). Common bean production was evaluated in winter season, and the best productions were observed in the plots with leguminous plants as green cover under 50 and $75 \mathrm{~kg}$.ha $\mathrm{h}^{-1}$ of $\mathrm{N}$. The rice grain production increased in the plot with Crotalaria juncea and Canavalia brasiliensis under 50 and $75 \mathrm{~kg}^{\text {.ha }}{ }^{-1}$ of N. Among the grass plants, Pennisetum glaucum was the green cover that promoted the best production for both sequential crops. The rice grain production decreased in the plot with Sorghum bicolor cv. AG-2501C and Sorghum bicolor guinea.

Key words: Phaseolus vulgaris L., Oryza sativa L. yield components, dry weight, crop rotation.

$\left({ }^{1}\right)$ Trabalho de Graduação do primeiro autor, apresentado à FCAV/UNESP, Jaboticabal (SP). Recebido para publicação 22 de abril de 2003 e aceito em 7 de outubro de 2003.

$\left({ }^{2}\right)$ Departamento de Controle de Qualidade - Sementes Monsoy-Monsanto, Caixa Postal, 112, 75650-000 Morrinhos (GO).

$\left({ }^{3}\right)$ Pós-Graduação/Departamento de ProduçãoVegetal - FCA/UNESP, Caixa Postal 237, 18603-970 Botucatu (SP). E-mail: rfarinelli@fca.unesp.br

$\left({ }^{4}\right)$ Departamento de Produção Vegetal - FCAV/UNESP, 14884-000, Jaboticabal (SP).

$\left({ }^{5}\right)$ Bolsita CAPES. 


\section{INTRODUÇÃO}

Como alternativa para se tentar evitar os processos de degradação do solo iniciou-se, nos anos 60 e 70, a introdução de sistemas de cultivo mínimo e de semeadura direta na Região Sul do Brasil (CASTRO Filho et al., 1993). Verificou-se que, para o sucesso do sistema semeadura direta, são requisitos fundamentais o planejamento de um sistema de rotação de culturas (CRUZ et al., 2001) e o manejo de restos culturais e de culturas de cobertura do solo (ALVARENGA et al., 2001). Dessa forma, viabilizou-se, em vastas áreas agrícolas do país, a adoção do sistema de semeadura direta em áreas cultivadas com soja e milho.

Entretanto, para o feijoeiro comum há necessidade de se realizar mais trabalhos experimentais em sistema de semeadura direta, pois a rotação de culturas e a adubação verde podem influenciar a produtividade da cultura (WUTKE et al., 1998). ARF et al. (1999), avaliando a incorporação de mucuna-preta, lablabe e de restos culturais de milho, no desenvolvimento e na produtividade do feijoeiro de inverno, verificaram que a produtividade de feijão com a mucuna-preta foi praticamente duplicada em relação ao tratamento de palhada de milho, e as maiores produtividades foram obtidas com mucuna-preta, lablabe e milho + mucuna-preta.

Entre os nutrientes, o nitrogênio é o elemento requerido em maior quantidade pelo feijoeiro e, dependendo da cultivar, apresenta maior ou menor capacidade de fixação do nitrogênio atmosférico pela ação das bactérias fixadoras de $\mathrm{N}_{2}$, presentes em nódulos formados no sistema radicular.

A quantidade de nitrogênio a ser empregada na adubação do feijoeiro pode estar condicionada ao tipo de planta de cobertura (gramínea ou leguminosa) que se cultiva na área, em sistema de semeadura direta. Em material com relação $\mathrm{C} / \mathrm{N}$ maior que 20, característica da maioria das gramíneas, há maior imobilização de nitrogênio para sua decomposição (Alvarenga et al., 2001), sendo necessário maior quantidade desse nutriente para obter resultados satisfatórios na colheita de feijão.

A cultura do arroz de terras altas é importante e, atualmente, tem sido o desafio da pesquisa em minimizar os riscos de seu cultivo por meio do sistema de semeadura direta. Esse sistema mostrou-se limitante à produtividade do arroz-de-sequeiro no Centro-Norte do Mato Grosso, onde se verificou a produtividade de $1.655 \mathrm{~kg} \cdot \mathrm{ha}^{-1} \mathrm{com}$ semeadura direta, de $1.835 \mathrm{~kg} \cdot \mathrm{ha}^{-1}$ com gradagens contínuas, e de 3.093 $\mathrm{kg} \cdot \mathrm{ha}^{-1}$ quando se utilizou aração profunda com arado de aiveca (SÉGUY e BouZINAC, 1996).
A resposta negativa do arroz de terras altas em semeadura direta é conseqüência, principalmente, de sua grande exigência em macroporosidade no perfil do solo. O espaço poroso no perfil do solo com rotação soja-arroz, praticada em semeadura direta só nas restevas, são insuficientes, pelo menos no início, para assegurar um desenvolvimento radicular mais vigoroso, necessário à obtenção de altas produtividades estáveis (SÉGUY et al., 1999). Também StONE et al. (1980) obtiveram menores produtividades de arroz de terras altas sob semeadura direta, em Latossolo Vermelho-Amarelo distrófico.

O nitrogênio é o segundo nutriente mais exigido pela cultura do arroz e o mais exportado como produto colhido (ForNASIERI FILHO, 1982) sendo, segundo Peters e Calvert (1982), o elemento que mais limita sua produção. No entanto, a resposta dessa cultura à adubação nitrogenada é variável, ora apresentando incremento de produtividade com doses superiores a 100 kg.ha ${ }^{-1}$ de N (STONE et al., 1999), ora não mostrando influência nem mesmo sobre componentes da produção e rendimento de engenho (ARF et al., 2003).

Dessa maneira, objetivo do presente trabalho foi, com apenas um ciclo de seqüencias de culturas, determinar a viabilidade agronômica dos cultivos de feijão bravo do Ceará (Canavalia brasiliensis), Crotalária juncea, milheto, sorgo de duplo propósito e sorgo de guiné, semeados no período de safrinha como cobertura morta, para a adoção do sistema de semeadura direta, bem como seus efeitos sobre o cultivo de feijão e arroz em sucessão, adubados com doses de nitrogênio em cobertura.

\section{MATERIAL E MÉTODOS}

O experimento foi desenvolvido na Faculdade de Ciências Agrárias e Veterinárias de Jaboticabal/ UNESP, em Latossolo Vermelho (EMBRAPA, 1999), durante os meses de março de 2000 a abril de 2001.

Inicialmente, a área experimental foi manejada apenas com o uso de herbicida, sendo utilizada a dose de 2,4 kg.ha ${ }^{-1}$ i.a. de glyphosate. A seguir, foram coletadas amostras de solo para análise química, na camada de 0-0,20 m. As análises, realizadas conforme RAIJ (1987), apresentaram como resultado $\mathrm{pH}$ $\left(\mathrm{CaCl}_{2}\right)=5,3$; M.O $\left(\mathrm{g} \cdot \mathrm{dm}^{-3}\right)=29$; P resina $\left(\mathrm{mg} \cdot \mathrm{dm}^{-3}\right)=$ $50 ; \mathrm{K}^{+}, \mathrm{Ca}^{2+}, \mathrm{Mg}^{2+}, \mathrm{H}+\mathrm{Al}, \mathrm{SB}, \mathrm{CTC}\left(\mathrm{mmol}_{\mathrm{c}} \cdot \mathrm{dm}^{-3}\right)=3,9$; $32 ; 11 ; 34 ; 47$ e 81 , respectivamente, e V $(\%)=58$.

Em 10 de março de 2000, uma semana após a dessecação da vegetação espontânea, procedeu-se a semeadura dos adubos verdes, em parcelas de $23 \mathrm{~m}$ de comprimento por $7 \mathrm{~m}$ de largura, distribuídas em 
blocos ao acaso, com quatro repetições. Foram semeados feijão bravo do Ceará (Canavalia brasiliensis); Crotalaria juncea cv. IAC-KR1; milheto cv. BN-2 (Pennisetum glaucum); sorgo de duplo propósito cv. AG2501C (Sorghum bicolor); sorgo de guiné (Sorghum bicolor tipo guinea) nas seguintes quantidades de sementes: 25 kg.ha ${ }^{-1}, 30$ kg.ha ${ }^{-1}, 20$ kg.ha ${ }^{-1}, 10$ kg.ha ${ }^{-1}$ e $10 \mathrm{~kg} \cdot \mathrm{ha}^{-1}$ respectivamente, além de um tratamento mantido no limpo, considerado como testemunha, na mesma dimensão descrita acima.

A semeadura foi feita a lanço e a incorporação com grade niveladora semifechada. A dureza do tegumento das sementes de feijão bravo do Ceará foi superada mediante a imersão prévia em água fervente durante 30 segundos. As parcelas mantidas no limpo foram manejadas com herbicida para evitar o estabelecimento de plantas invasoras.

Aos 70 dias após a semeadura, realizou-se a dessecação dos adubos verdes com glyphosate na dose de 2,4 kg.ha ${ }^{-1}$ i.a. e 2,4 D amina na dose de 806 g.ha $^{-1}$ i.a. , com volume de calda de 300 L.ha ${ }^{-1}$. Em seguida, foi passado o rolo-faca, para acamamento e picagem do material. Procedeu-se a amostragens de fitomassa, em três locais de cada parcela com adubo verde, por meio de uma armação de ferro de $1 \mathrm{~m}^{2}$ de área útil, para as determinações de produção de matéria seca, teores de macronutrientes e cálculo de extração de nutrientes. Avaliou-se, ainda, utilizando uma carta de espacialização, a porcentagem de cobertura do solo, mediante a distribuição percentual das áreas cobertas. As amostragens de fitomassa, bem como a avaliação da porcentagem de cobertura foram efetuadas após cinco dias do manejo com rolo-faca.

Em $1 .^{\circ}$ de junho de 2000, foi semeado em sistema de semeadura direta o feijão "de inverno", cultivar Pérola, tipo comercial Carioca, hábito de crescimento indeterminado entre os tipos II e III, porte semi-ereto, floração média em 46 dias. A semeadura foi realizada mecanicamente, utilizando-se 14 sementes por metro linear, no espaçamento entre linhas de $0,45 \mathrm{~m}$, em um total de 15 linhas de planta por subparcela.

Os tratamentos foram distribuídos em blocos ao acaso em esquema de parcelas subdivididas, sendo as parcelas compostas pelos adubos verdes e testemunha no limpo, e as subparcelas dispostas em $5 \mathrm{~m}$ de comprimento por $7 \mathrm{~m}$ de largura, constituídas de doses de nitrogênio $\left(0,25,50\right.$ e $75 \mathrm{~kg} \cdot \mathrm{ha}^{-1}$ de $\left.\mathrm{N}\right)$, tendo como fonte a uréia, aplicadas em cobertura.

A adubação de semeadura foi empregada de acordo com a análise do solo, utilizando-se a formulação comercial 02-25-15 na dose de $150 \mathrm{~kg}$.ha ${ }^{-1}$, objetivando-se uma produtividade esperada de 3,0 t.ha ${ }^{-1}$ de grãos, segundo AmBrosano et al. (1997).
Realizou-se a adubação nitrogenada em cobertura no estádio R5, caracterizado na fase de botões florais (pré-florescimento) aos 30 dias após a emergência das plantas, e sua imediata incorporação pela água da irrigação, através de uma lâmina de 15 mm.

Quanto ao atendimento das exigências de água pela cultura do feijão, utilizou-se irrigação complementar de acordo com sua fase e necessidade hídrica, pelo sistema convencional por aspersão.

No fim do ciclo da cultura do feijão foram coletadas 10 plantas por subparcela, nas quais se determinaram os seguintes componentes da produção: número de vagens por planta; número de grãos por planta; número de grãos por vagem; massa de 1.000 grãos em duas amostras por subparcela (13\% em base úmida).

Para determinar a produtividade de grãos, procedeu-se o arranquio manual das plantas na área útil de cada subparcela, considerando-se como bordadura as quatro linhas externas de cada lado, e separadas em trilhadora de parcela. Os grãos foram pesados em balança eletrônica, retirando-se uma amostra para determinar a umidade e corrigir os valores da produtividade para o teor de água a 13\% em base úmida. Determinou-se, ainda, o teor de proteína bruta nos grãos, após sua moagem, realizando a quantificação do teor de nitrogênio e multiplicandose o valor obtido pelo fator 6,25 (SARRUGE e HAAG, 1974).

Após a colheita da cultura do feijão, foi realizada a aplicação de herbicida de manejo, utilizando a dose de 2,4 kg.ha ${ }^{-1}$ i.a. de glyphosate e 2,4 D amina na dose de 806 g.ha $^{-1}$ i.a., para eliminar as plantas daninhas infestantes na área.

A semeadura do arroz, cv. IAC 202, foi feita em 21 de novembro de 2000, quinze dias após a aplicação do herbicida em cada subparcela, onde anteriormente fora cultivado o feijoeiro em dez linhas espaçadas de 0,45 m, colocando-se 100 sementes viáveis por metro quadrado.

Aplicou-se adubação básica de semeadura, segundo CANTARELla e FurLani (1997), para uma produtividade esperada de 3,0 t.ha ${ }^{-1}$ de grãos, empregando-se $250 \mathrm{~kg} \cdot \mathrm{ha}^{-1}$ da fórmula comercial 0225-15. No início da fase reprodutiva (ponto algodão) foi utilizada adubação nitrogenada em cobertura, nas mesmas doses de 0, 25, 50 e $75 \mathrm{~kg}$.ha ${ }^{-1}$, sendo a fonte de nitrogênio a uréia; logo após a adubação, aplicouse uma lâmina de água de $15 \mathrm{~mm}$ por aspersão com a finalidade de incorporação do fertilizante.

Assim como para a cultura do feijão, também foi utilizada irrigação complementar, de acordo com a fase e necessidade hídrica da cultura do arroz, pelo sistema convencional por aspersão. 
Antecedendo a operação de colheita foram coletadas, na área útil de cada subparcela, todas as panículas em 1,0 m de linha para determinar os seguintes componentes da produção: número de panículas por metro quadrado; número de espiguetas cheias por panícula; porcentagem de espiguetas estéreis, determinada em 1.000 espiguetas ao acaso, colocadas em balde com água, sendo contados o número de espiguetas que boiaram; massa de 1.000 grãos em duas amostras por subparcela (13\% base úmida).

A colheita do arroz foi realizada manualmente aos 135 dias após a semeadura, quando os grãos das panículas apresentavam-se duros. A seguir, procederam-se a separação e abanação manual com auxílio de peneira. Em seguida, determinou-se a massa dos grãos colhidos e calculou-se a produtividade de grãos em 13\% base úmida. Os grãos foram armazenados em condições de laboratório por cerca de 30 dias, sendo coletada uma amostra de $100 \mathrm{~g}$ de grãos de arroz em casca, levada ao engenho de prova (Suzuki), modelo MT, e processada para determinar a renda de grãos sem casca. A seguir, os grãos foram colocados no engenho de prova por um minuto para brunir, obtendo-se a renda de benefício. Posteriormente, os grãos brunidos (polidos) foram colocados no "trieur" n. ${ }^{\circ} 2$, no qual se processou a separação dos grãos, por 30 segundos, obtendo-se a renda de grãos inteiros.

Determinou-se o teor de proteína bruta dos grãos pela moagem dos grãos brunidos, e quantificação do teor de nitrogênio, multiplicando-se o valor obtido pelo fator 6,25 (SARRUGE e HAAG, 1974).

Os resultados obtidos para os adubos verdes, para a cultura de feijão e arroz, foram avaliados estatisticamente através da análise de variância utilizando o teste $\mathrm{F}$, seguindo o modelo de blocos ao acaso em parcelas subdivididas e as médias comparadas pelo teste de Tukey a 5\% de probabilidade. Utilizou-se também a análise de regressão polinomial para as doses de nitrogênio.

\section{RESULTADOS E DISCUSSÃO}

O quadro 1 apresenta os resultados da produção de matéria seca e da porcentagem de cobertura vegetal do solo proporcionada pelas espécies utilizadas como adubos verdes. Os maiores valores desses parâmetros foram obtidos com as gramíneas, sobressaindo-se o sorgo guiné e o sorgo AG-2501C.

$\mathrm{Na}$ avaliação de cobertura de solo, realizada após a dessecação dos adubos verdes, todas as gramíneas proporcionaram $100 \%$ de cobertura vegetal, o que pode estar relacionado ao seu maior desenvolvimento vegetativo. De modo geral, os adubos verdes apresentaram boa cobertura vegetal do solo, em comparação com a testemunha que permaneceu "no limpo", proporcionando maior proteção ao solo contra erosão hídrica e eólica, redução nas amplitudes térmicas, menores taxas de evaporação de água e condições favoráveis ao desenvolvimento de organismos vivos. Torna-se relevante o fato de a cobertura vegetal ser desenvolvida no período da "safrinha", quando os baixos índices pluviométricos são fatores limitantes às culturas comerciais de verão.

Os resultados de produção de matéria seca obtidos pelas leguminosas foram superiores em mais de 30\% aos encontrados por PRIMAVESI et al. (1996 a), em trabalho com adubos verdes, cortados com 90 dias na época de "verão", em Latossolo Vemelho-Amarelo e Latossolo Vermelho-Escuro.

Quadro 1. Produção de matéria seca, após período vegetativo de 70 dias e porcentagem de cobertura vegetal do solo, de espécies leguminosas e gramíneas, utilizadas como adubos verdes, no período da "safrinha". Jaboticabal (SP), 2000

\begin{tabular}{lcr}
\hline Adubos verdes & Produção de matéria seca & Cobertura do solo \\
\hline Canavalia brasiliensis & $\mathrm{kg} \cdot \mathrm{ha}^{-1}$ & \% \\
Crotalaria juncea cv IAC-KR1 & $6275 \mathrm{c}$ & $60 \mathrm{c}$ \\
Pennisetum glaucum cv. BN-2 & $6854 \mathrm{c}$ & $100 \mathrm{a}$ \\
Sorghum bicolor cv. AG-2501C & $9579 \mathrm{~b}$ & $100 \mathrm{a}$ \\
Sorghum bicolor tipo guinea & $12686 \mathrm{a}$ & $100 \mathrm{a}$ \\
\hline Teste F & $12814 \mathrm{a}$ & $289,73 * *$ \\
C.V. $(\%)$ & $54,69 * *$ & 3,9 \\
\hline
\end{tabular}

Obs. ${ }^{*}$ - significativo a $1 \%$ de probabilidade pelo teste F. Médias seguidas de mesma letra na coluna, não diferem entre si ao nível de $5 \%$ pelo teste de Tukey. 
Por outro lado, para o milheto, esses autores verificaram uma produção de 14 t.ha ${ }^{-1}$ de matéria seca, acima do obtido no presente trabalho. CARVALHO (2000) obteve valores pouco superiores para o milheto (aproximadamente 10 t.ha $^{-1}$ ) e inferiores para a crotalária (aproximadamente 5 t.ha ${ }^{-1}$ ), tendo sido realizado o corte aos 70 dias após a semeadura.

A C. brasiliensis destacou-se pela maior absorção de nitrogênio, e a incorporação desse material indicaria uma adubação orgânica de quase $100 \mathrm{~kg} \cdot \mathrm{ha}^{-1}$ de $\mathrm{N}$ ao solo (Quadro 2). Do sorgo guiné, observouse elevada extração de nutrientes, principalmente potássio, fósforo, magnésio e enxofre, demonstrando que a utilização de espécies vegetais, na forma de adubação verde, atua na ciclagem de nutrientes que se encontram, muitas vezes, indisponíveis às culturas anuais em razão da profundidade no solo. No caso das leguminosas, a fixação biológica de $\mathrm{N}_{2}$ atmosférico proporciona seu fornecimento posterior às culturas agrícolas. Esses valores são semelhantes aos de $\mathrm{N}$ e K, obtidos por Primavesi et al. (1996 b) em C. ensiformis, $C$. juncea e $P$. americanum.

No quadro 3 estão apresentados os resultados dos componentes da produção e produtividade de grãos de feijoeiro. Para a maioria das características avaliadas, obtiveram-se efeitos significativos para os adubos verdes e para as doses da adubação nitrogenada, bem como na interação adubos verdes ' doses de $\mathrm{N}$ para produtividade de grãos e produção de proteína bruta.
Os maiores valores de produtividade de grãos e dos demais componentes da produção foram obtidos no feijoeiro cultivado em sucessão às leguminosas. Quaisquer sorgos proporcionaram as menores produtividades de feijão, sendo o componente produtivo, representado por número de vagens por planta, o mais afetado pelos restos vegetais de ambas as gramíneas (Quadro 3).

Esses resultados concordam com WUTKE et al. (1998) que, em trabalho desenvolvido no município de Ribeirão Preto (SP), com aveia-preta, crotalária juncea, guandu e mucuna-preta, obtiveram maior produtividade na área com mucuna-preta, que não diferiu da crotalária. ARF et al. (1999) e CARVALHO (2000), avaliando o efeito da rotação de culturas e da adubação verde sobre a produtividade do feijoeiro, não verificaram influência alguma nas características agronômicas avaliadas nem na produtividade de grãos.

Em relação à adubação nitrogenada em cobertura, verificou-se influência positiva nos componentes da produção, exceto no número de grãos por vagem.

As maiores produtividades de feijão foram obtidas com a utilização de 50 e $75 \mathrm{~kg} \cdot \mathrm{ha}^{-1}$ de $\mathrm{N}$ e os maiores teores de proteína nos grãos com $75 \mathrm{~kg}$.ha ${ }^{-1}$ de N. Esses resultados concordam com os obtidos por DiNIZ (1995), que verificou aumento de produtividade de $19 \%$ a $39 \%$, em virtude da adubação nitrogenada em cobertura.

Quadro 2. Extração de macronutrientes por espécies leguminosas e gramíneas, cultivadas como adubos verdes, no período da "safrinha". Jaboticabal (SP), 2000

\begin{tabular}{|c|c|c|c|c|c|c|}
\hline Adubos verdes & $\mathrm{N}$ & $\mathrm{P}$ & $\mathrm{K}$ & $\mathrm{Ca}$ & $\mathrm{Mg}$ & S \\
\hline & & & -1 & & & \\
\hline Canavalia brasiliensis & 107,7 a & $13,9 \mathrm{~b}$ & $80,3 \mathrm{c}$ & 115,3 a & $11,6 \mathrm{~b}$ & $11,0 \mathrm{~b}$ \\
\hline \multicolumn{7}{|l|}{ Crotalaria juncea } \\
\hline cv. IAC-KR1 & $83,7 \mathrm{ab}$ & $6,9 \mathrm{c}$ & $72,4 \mathrm{c}$ & $43,2 \mathrm{~b}$ & $11,3 \mathrm{~b}$ & $4,7 \mathrm{c}$ \\
\hline \multicolumn{7}{|l|}{ Pennisetum glaucum } \\
\hline $\mathrm{cv} \cdot \mathrm{BN}-2$ & $58,1 \mathrm{c}$ & $8,8 \mathrm{c}$ & $116,0 \mathrm{~b}$ & $18,3 \mathrm{c}$ & $12,7 \mathrm{~b}$ & $7,1 \mathrm{c}$ \\
\hline \multicolumn{7}{|l|}{ Sorghum bicolor } \\
\hline cv. AG-2501C & $79,8 \mathrm{bc}$ & $17,7 \mathrm{ab}$ & $119,7 \mathrm{~b}$ & $26,6 \mathrm{bc}$ & $25,5 \mathrm{a}$ & $7,1 \mathrm{c}$ \\
\hline \multicolumn{7}{|l|}{ Sorghum bicolor } \\
\hline tipo guinea & $90,3 \mathrm{ab}$ & $20,5 \mathrm{a}$ & 219,8 a & $42,6 \mathrm{~b}$ & $27,6 \mathrm{a}$ & $21,1 \mathrm{a}$ \\
\hline Teste F & $11,06^{* *}$ & $41,49^{* *}$ & $64,23^{* *}$ & $90,23^{* *}$ & $82,64^{* *}$ & $71,66^{* *}$ \\
\hline C.V. $(\%)$ & 12,9 & 13,2 & 12,1 & 16,5 & 10,0 & 15,1 \\
\hline
\end{tabular}

Obs. ** - significativo a $1 \%$ de probabilidade pelo teste F. Médias seguidas de mesma letra na coluna, não diferem entre si ao nível de $5 \%$ pelo teste de Tukey. 
Quadro 3. Produtividade de grãos e componentes da produção do feijoeiro "de inverno", após o cultivo anterior com adubos verdes e em função da adubação nitrogenada. Jaboticabal (SP), 2000

\begin{tabular}{|c|c|c|c|c|c|c|c|}
\hline Adubos verdes & $\begin{array}{c}\text { Vagens } \\
\text { por planta }\end{array}$ & $\begin{array}{c}\text { Grãos por } \\
\text { vagem }\end{array}$ & $\begin{array}{c}\text { Grãos por } \\
\text { planta }\end{array}$ & $\begin{array}{c}\text { Massa } \\
1.000 \text { grãos }\end{array}$ & $\begin{array}{l}\text { Produtividade } \\
\text { de grãos }\end{array}$ & $\begin{array}{l}\text { Teor de } \\
\text { proteína } \\
\text { no grão }\end{array}$ & $\begin{array}{c}\text { Produtividade } \\
\text { de proteína }\end{array}$ \\
\hline & 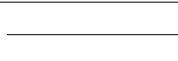 & $\mathrm{n}^{\circ}$ & 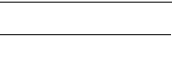 & $\mathrm{g}$ & kg.ha ${ }^{-1}$ & $\mathrm{~g} \cdot \mathrm{kg}^{-1}$ & kg.ha ${ }^{-1}$ \\
\hline Testemunha "no limpo" & $13,9 \mathrm{ab}$ & $3,78 \mathrm{a}$ & $52,4 \mathrm{abc}$ & $275,8 \mathrm{a}$ & $1.849 \mathrm{bc}$ & $215 b$ & $398 \mathrm{~b}$ \\
\hline Canavalia brasiliensis & 15,0 a & 3,79 a & $56,8 \mathrm{ab}$ & $279,5 \mathrm{a}$ & $2.188 \mathrm{a}$ & $228 \mathrm{a}$ & $423 \mathrm{a}$ \\
\hline $\begin{array}{l}\text { Crotalaria juncea } \\
\text { cv. IAC-KR1 }\end{array}$ & 14,9 a & 4,00 a & 59,7 a & $272,2 \mathrm{a}$ & $2.177 \mathrm{a}$ & $219 \mathrm{ab}$ & $406 \mathrm{ab}$ \\
\hline $\begin{array}{l}\text { Pennisetum glaucum } \\
\text { cv.BN-2 }\end{array}$ & $13,3 \mathrm{~b}$ & $3,87 \mathrm{a}$ & $51,6 \mathrm{bc}$ & $270,2 \mathrm{a}$ & $2.008 \mathrm{ab}$ & $221 \mathrm{ab}$ & $409 \mathrm{ab}$ \\
\hline $\begin{array}{l}\text { Sorghum bicolor } \\
\text { cv. AG-2501C }\end{array}$ & $12,9 \mathrm{~b}$ & 3,86 a & $49,7 \mathrm{bc}$ & $283,0 \mathrm{a}$ & $1.750 \mathrm{c}$ & $213 \mathrm{~b}$ & $394 \mathrm{~b}$ \\
\hline $\begin{array}{l}\text { Sorghum bicolor } \\
\text { tipo guinea }\end{array}$ & $13,0 \mathrm{~b}$ & 3,74 a & $48,9 \mathrm{c}$ & $268,5 \mathrm{a}$ & $1.908 \mathrm{bc}$ & $222 \mathrm{ab}$ & $411 \mathrm{ab}$ \\
\hline C.V. $(\%)$ & 8,06 & 9,48 & 12,63 & 6,81 & 8,14 & 3,84 & 3,83 \\
\hline \multicolumn{8}{|l|}{ Doses } \\
\hline $0 \mathrm{~N}$ & $13,2 \mathrm{~b}$ & $3,84 \mathrm{a}$ & $50,8 \mathrm{~b}$ & $262,0 \mathrm{~b}$ & $1.708 \mathrm{c}$ & $204 \mathrm{~d}$ & $379 \mathrm{~d}$ \\
\hline $25 \mathrm{~N}$ & $13,7 \mathrm{ab}$ & 3,81 a & $52,3 \mathrm{ab}$ & $273,6 \mathrm{ab}$ & $1.995 \mathrm{~b}$ & $213 c$ & $395 \mathrm{c}$ \\
\hline $50 \mathrm{~N}$ & $14,2 \mathrm{a}$ & 3,82 a & $54,1 \mathrm{ab}$ & $280,0 \mathrm{a}$ & $2.091 \mathrm{a}$ & $221 \mathrm{~b}$ & $408 \mathrm{~b}$ \\
\hline $75 \mathrm{~N}$ & 14,3 a & 3,89 a & 55,6 a & $283,8 \mathrm{a}$ & $2.126 \mathrm{a}$ & $241 \mathrm{a}$ & 446 a \\
\hline C.V. $(\%)$ & 5,6 & 8,2 & 9,9 & 6,1 & 4,1 & 2,7 & 2,7 \\
\hline
\end{tabular}

Obs. Médias seguidas de mesma letra, na coluna, não diferem entre si ao nível de 5\% de probabilidade pelo teste de Tukey.

Procedeu-se o estudo de regressão polinomial das doses de $\mathrm{N}$ dentro de cada adubo verde, para a produtividade de grãos e teor de proteína bruta (Figuras 1 e 2). A utilização de leguminosas como cobertura morta proporcionou maiores produtividades, mesmo na ausência de adubação nitrogenada (Figura 1). A combinação C.juncea / feijoeiro atingiu um máximo de produtividade de grãos com a aplicação de 44 $\mathrm{kg} \cdot \mathrm{ha}^{-1}$ de $\mathrm{N}$, enquanto para C. brasiliensis, essa resposta foi observada com $52 \mathrm{~kg} \cdot \mathrm{ha}^{-1}$ de $\mathrm{N}$.

O cultivo do milheto antes do feijoeiro também favoreceu a produtividade de grãos e aumentou a resposta ao $\mathrm{N}$ aplicado em cobertura, embora, propiciando uma produtividade média de grãos $7 \%$ inferior àquela observada após o cultivo das leguminosas. Esse resultado deve-se, provavelmente, ao fato de as gramíneas possuírem uma relação $\mathrm{C} / \mathrm{N}$ mais ampla que as leguminosas (DERPSCH et al., 1985) e por ter sido produzida maior quantidade de matéria seca $\left(9.579,12.686\right.$ e $12.814 \mathrm{~kg} \cdot \mathrm{ha}^{-1}$, para milheto, sorgo cv. AG-2501C e sorgo guiné respectivamente), causando maior imobilização do $\mathrm{N}$ durante a decomposição dos resíduos e, conseqüentemente, menor disponibilidade deste nutriente às plantas de feijão. Contudo, as leguminosas estariam favorecendo o cultivo do feijoeiro, em parte, pela razão $\mathrm{C} / \mathrm{N}$ estreita, possibilitando rápida decomposição dos resíduos vegetais e maior disponibilidade do $\mathrm{N}$ e de outros nutrientes mineralizados para a cultura e, também, pela conhecida fixação simbiótica de $\mathrm{N}_{2}$ atmosférico, condicionando melhoria na fertilidade do solo.

Quanto ao teor de proteína bruta (Figura 2), verificou-se um comportamento quadrático crescente para C. brasiliensis. Na ausência da adubação nitrogenada, os tratamentos com adubos verdes proporcionaram maior teor de proteína bruta. 

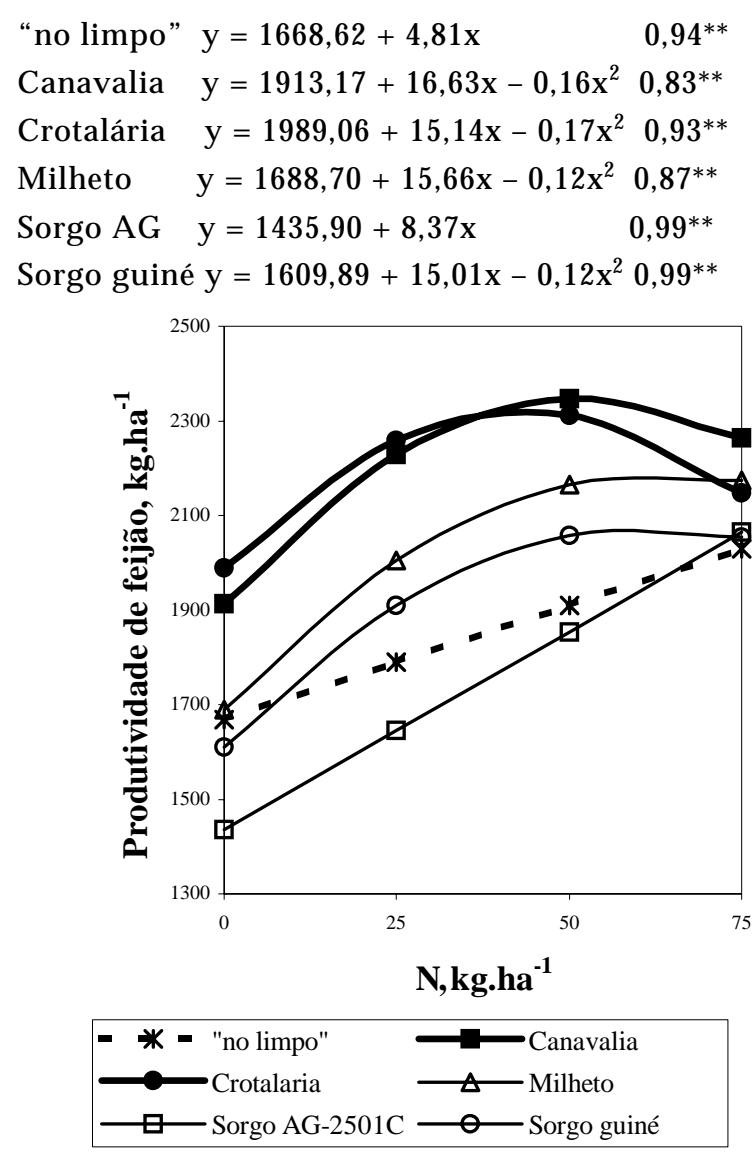

Figura 1. Doses de nitrogênio na produtividade de feijoeiro "de inverno", cultivado em sucessão de adubos verdes. Jaboticabal (SP), 2000.

Para a cultura do arroz, os maiores valores de produtividade de grãos e dos demais componentes da produção foram obtidos no cultivo nos resíduos de leguminosas / feijoeiro e do milheto/feijoeiro, com destaque para a utilização de $C$. juncea para a produtividade de grãos (Quadro 4). Pelo estudo de regressão polinomial da interação adubos verdes ' doses de $\mathrm{N}$, observou-se um aumento quadrático da produtividade de grãos de arroz para todas as combinações utilizadas em resposta à adubação nitrogenada, com exceção à sucessão sorgo guiné/ feijoeiro/arroz, cuja resposta foi linear (Figura 3a).

A maior produtividade foi alcançada com a rotação C.juncea/feijoeiro/arroz (3.039 kg.ha-1) e 75 $\mathrm{kg} \cdot \mathrm{ha}^{-1}$ de N, e a maior produtividade estimada (3.044 $\mathrm{kg} \cdot \mathrm{ha}^{-1}$ ) seria na dose de aproximadamente $80 \mathrm{~kg} \cdot \mathrm{ha}^{-1}$ de N. Na testemunha mantida "no limpo", a produtividade máxima foi de $2.158 \mathrm{~kg} \cdot \mathrm{ha}^{-1}$, na dose de 55 kg.ha ${ }^{-1}$ de N. Nessa mesma dose, com o cultivo de $C$. juncea / feijoeiro, a produtividade foi de aproximadamente $2.897 \mathrm{~kg} \cdot \mathrm{ha}^{-1}$, resultando em um ganho de aproximadamente $34 \%$.

$$
\begin{array}{llc}
\text { "no limpo" } y=192,70+0,59 x & 0,96^{* *} \\
\text { Canavalia } & y=198,00+0,1 x+0,01 x^{2} & 0,98^{* *} \\
\text { Crotalária } & y=215,05+0,1 x & 0,69^{* *} \\
\text { Milheto } & y=199,02+0,58 x & 0,94^{* *} \\
\text { Sorgo AG } & y=209,57+0,09 x & 0,88^{* *} \\
\text { Sorgo guiné } y=212,96+0,43 x-0,01 x^{2} & 0,91^{* *}
\end{array}
$$
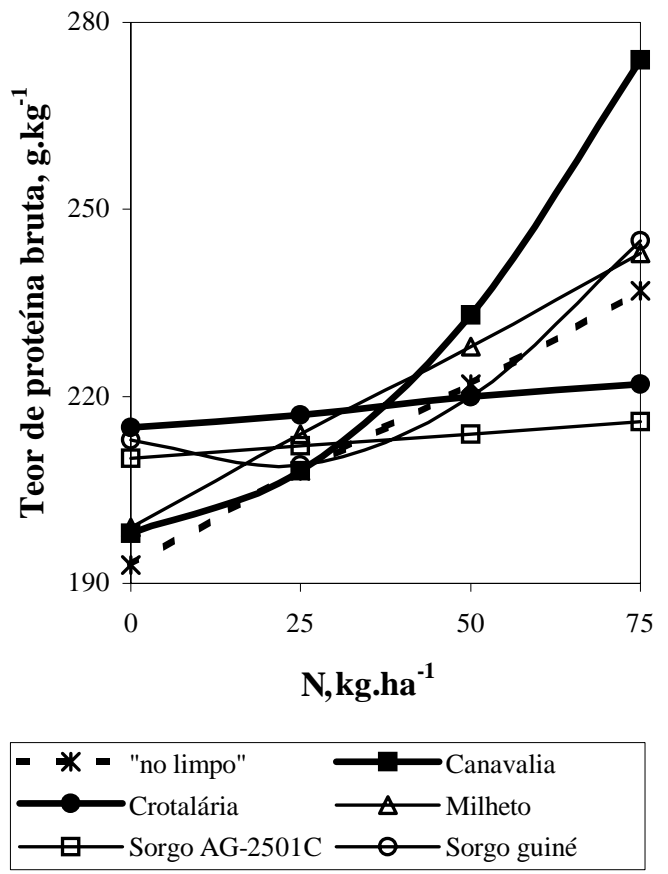

Figura 2. Doses de nitrogênio no teor de proteína bruta presente em grãos de feijoeiro "de inverno", cultivado em sucessão de adubos verdes. Jaboticabal (SP), 2000

Pôde-se ainda observar que, mesmo sem adubação em cobertura, houve maior produtividade naquelas áreas anteriormente cultivadas com adubos verdes, exceção as dos sorgos AG-2501C e guiné. Esses resultados estão de acordo com aqueles obtidos por MARENCO e SANTOS (1999), que observaram maior produtividade de arroz em rotação com crotalária e mucuna do que com arroz em cultivo sucessivo.

No presente estudo, na ausência de adubação nitrogenada, a maior produtividade ocorreu na rotação milheto/feijoeiro/arroz, com produtividade de grãos 33\% maior em relação ao tratamento "no limpo" / feijoeiro/arroz (Figura 3a). Esse comportamento foi provavelmente devido à maior formação de cobertura vegetal dada pelo milheto em comparação às leguminosas (Quadro 1) e que pela relação $\mathrm{C} / \mathrm{N}$ ampla, estaria ainda disponibilizando $\mathrm{N}$ às plantas, na época de cultivo do arroz.

Para os sorgos AG-2501C e guiné, observouse que a produtividade de grãos de arroz de terras altas foi inferior em todas as doses de adubação. 
$\begin{array}{lll}\text { “limpo" } & \mathrm{y}=1427,1+26,5 \mathrm{x}-0,24 \mathrm{x}^{2} & 0,78^{* *} \\ \text { Canavalia } & \mathrm{y}=1830,3+31,6 \mathrm{x}-0,37 \mathrm{x}^{2} & 0,99^{* *} \\ \text { Crotalária } & \mathrm{y}=1500,3+38,8 \mathrm{x}-0,24 \mathrm{x}^{2} & 0,96^{* *} \\ \text { Milheto } & \mathrm{y}=1897,9+15,4 \mathrm{x}-0,11 \mathrm{x}^{2} & 0,92^{* *} \\ \text { Sorgo AG } & \mathrm{y}=865,6+25,4 \mathrm{x}-0,25 \mathrm{x}^{2} & 0,99^{* *} \\ \text { Sorgo guiné } & \mathrm{y}=1229,2+4,77 \mathrm{x} & 0,90^{* *}\end{array}$

(a)

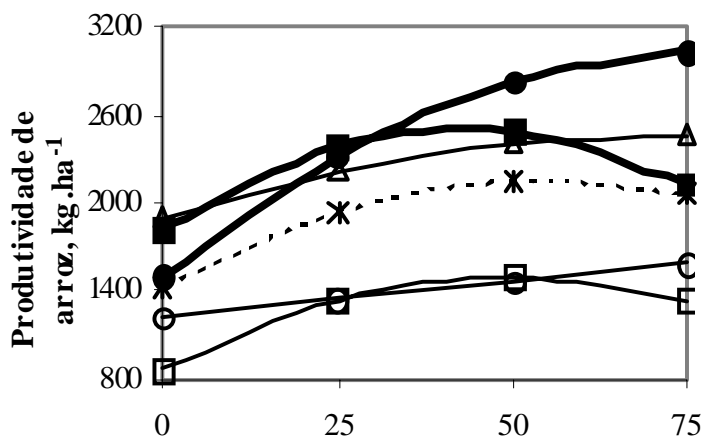

$\mathbf{N}$, kgha $^{-1}$

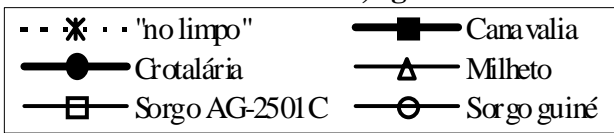

$\begin{array}{llc}\text { “limpo” } & \mathrm{y}=64,62+0,79 \mathrm{x}-0,01 \mathrm{x}^{2} & 0,56^{* *} \\ \text { Canavalia } & \mathrm{y}=85,65+0,42 \mathrm{x}-0,005 \mathrm{x}^{2} & 0,95^{\mathrm{ns}} \\ \text { Crotalária } & \mathrm{y}=71,77+0,54 \mathrm{x} & 0,82^{* *} \\ \text { Milheto } & \mathrm{y}=63,58+0,19 \mathrm{x} & 0,82^{* *} \\ \text { Sorgo AG } & \mathrm{y}=33,85+1,40 \mathrm{x}-0,01 \mathrm{x}^{2} & 0,98^{* *} \\ \text { Sorgo guiné } & \mathrm{y}=41,44+0,03 \mathrm{x}+0,01 \mathrm{x}^{2} & 0,99^{* *}\end{array}$

(c)

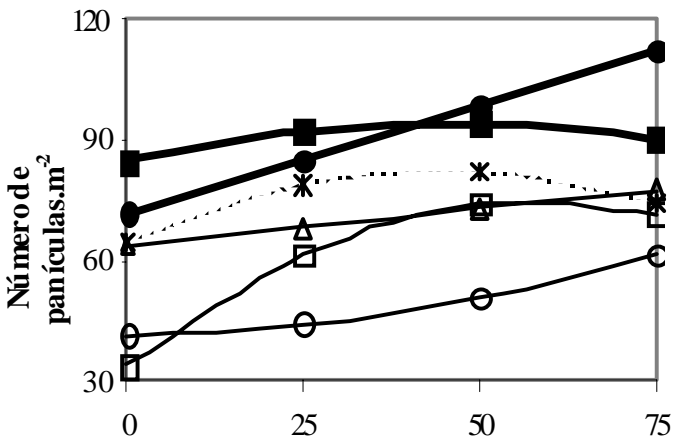

N, kgha $^{-1}$

$\begin{array}{cl}\text { * "nolimpo" } & - \text { Canavalia } \\ \text {-Crotalária } & \Delta \text { Milheto } \\ \text { —-Sorgo AG-2501C } & - \text { - Sorgo guiné }\end{array}$

$\begin{array}{ll}\text { “limpo" } & \mathrm{y}=117,92+2,30 \mathrm{x}-0,02 \mathrm{x}^{2} 0,78^{* *} \\ \text { Canavalia } & \mathrm{y}=157,96+2,50 \mathrm{x}-0,03 \mathrm{x}^{2} 1,00^{* *} \\ \text { Crotalária } & \mathrm{y}=122,92+3,37 \mathrm{x}-0,02 \mathrm{x}^{2} 0,98^{* *} \\ \text { Milheto } & \mathrm{y}=151,49+1,86 \mathrm{x}-0,01 \mathrm{x}^{2} 0,96^{* *} \\ \text { Sorgo AG } & \mathrm{y}=70,08+2,28 \mathrm{x}-0,02 \mathrm{x}^{2} \quad 0,99^{* *} \\ \text { Sorgo guiné } & \mathrm{y}=106,8+0,38 \mathrm{x}-0,003 \mathrm{x}^{2} \quad 0,89^{* *}\end{array}$

(b)

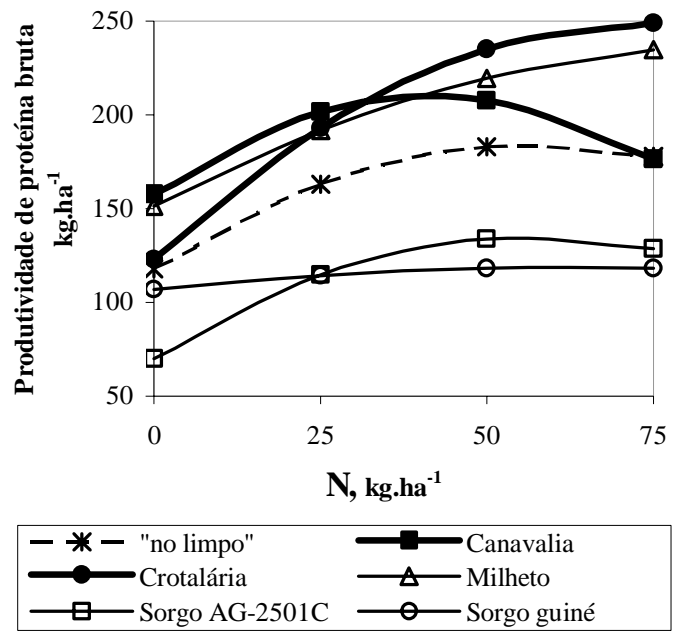

"limpo" $\quad \mathrm{y}=23,42+0,02 \mathrm{x}-0,001 \mathrm{x}^{2} \quad 0,53^{\text {ns }}$

Canavalia $\quad \mathrm{y}=23,76+0,01 \mathrm{x}-0,001 \mathrm{x}^{2} 0,90^{* *}$

Crotalária $\mathrm{y}=23,64+0,02 \mathrm{x}-0,001 \mathrm{x}^{2} \quad 0,97^{*}$

Milheto $\quad y=24,0+0,001 x+0,0001 x^{2} 0,93^{\text {ns }}$

Sorgo AG $y=22,82+0,04 x-0,001 x^{2} 0,98^{* *}$

Sorgo guiné $y=22,28+0,016 x \quad 0,91^{* *}$

(d)

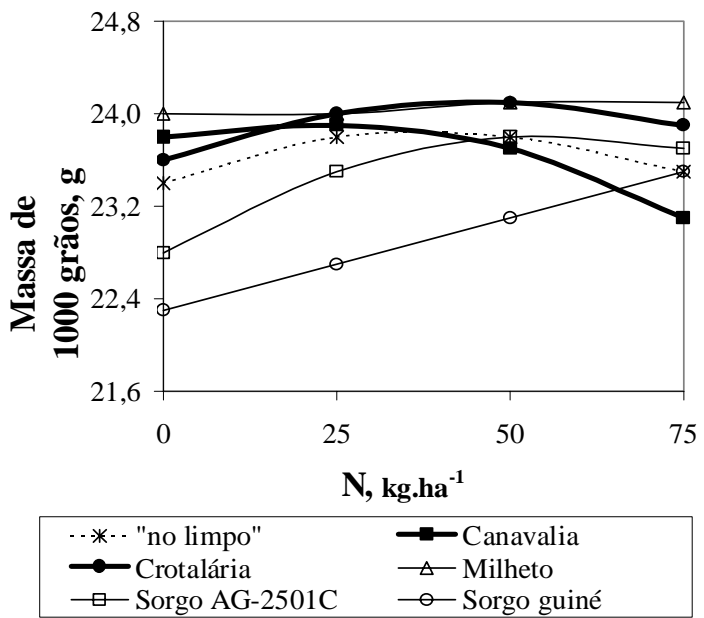

Figura 3. Interação adubos verdes $x$ doses de $\mathrm{N}$ na cultura do arroz sobre: (a) produtividade; (b) produtividade de proteína bruta; (c) número de panículas por metro quadrado; (d) massa de 1000 grãos. Jaboticabal (SP), 2000. 
Quadro 4. Componentes da produção e produtividade de grãos do arroz de terras altas, em sucessão ao feijoeiro, em função de adubos verdes e adubação nitrogenada. Jaboticabal (SP), 2000

\begin{tabular}{|c|c|c|c|c|c|c|}
\hline Adubos verdes & $\begin{array}{l}\text { Panículas } \\
\text { por } \mathrm{m}^{-2}\end{array}$ & $\begin{array}{c}\text { Espiguetas cheias } \\
\text { por panícula }\end{array}$ & $\begin{array}{c}\text { Espiguetas } \\
\text { estéreis }\end{array}$ & $\begin{array}{l}\text { Massa de } \\
1000 \text { grãos }\end{array}$ & $\begin{array}{l}\text { Produtividade } \\
\text { de grãos }\end{array}$ & $\begin{array}{l}\text { Produtividade } \\
\text { de proteína bruta }\end{array}$ \\
\hline & 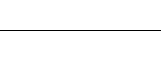 & $n^{\circ}$ & $\%$ & $\mathrm{~g}$ & kg.ha ${ }^{-1}$ & kg.ha ${ }^{-1}$ \\
\hline Testemunha "no limpo" & $75,0 \mathrm{~b}$ & $114 \mathrm{c}$ & $13,1 \mathrm{a}$ & $23,6 \mathrm{bc}$ & 1895 c & $158,4 \mathrm{~b}$ \\
\hline Canavalia brasiliensis & $90,4 \mathrm{a}$ & $134 \mathrm{a}$ & $11,7 \mathrm{abc}$ & $23,6 \mathrm{bc}$ & $2211 b$ & $188,4 \mathrm{a}$ \\
\hline $\begin{array}{l}\text { Crotalaria juncea } \\
\text { cv IAC-KR1 }\end{array}$ & 91,9 a & $123 \mathrm{~b}$ & $10,6 \mathrm{c}$ & $23,9 \mathrm{ab}$ & 2424 a & 206,7 a \\
\hline $\begin{array}{l}\text { Pennisetum glaucum } \\
\mathrm{cv} . \mathrm{BN}-2\end{array}$ & $70,6 \mathrm{bc}$ & $123 \mathrm{~b}$ & $11,6 \mathrm{bc}$ & $24,1 \mathrm{a}$ & $2245 \mathrm{~b}$ & 189,8 a \\
\hline $\begin{array}{l}\text { Sorghum bicolor } \\
\text { cv. AG-2501C }\end{array}$ & $60,3 \mathrm{~cd}$ & $108 \mathrm{~d}$ & $12,6 \mathrm{ab}$ & $23,5 \mathrm{c}$ & $1262 \mathrm{e}$ & $120,0 \mathrm{c}$ \\
\hline $\begin{array}{l}\text { Sorghum bicolor } \\
\text { tipo guinea }\end{array}$ & $49,4 \mathrm{~d}$ & $116 \mathrm{c}$ & $10,4 \mathrm{c}$ & $22,9 \mathrm{~d}$ & $1408 \mathrm{~d}$ & $127,4 \mathrm{c}$ \\
\hline C.V. $(\%)$ & 14,03 & 4,21 & 11,32 & 1,19 & 6,55 & 9,99 \\
\hline \multicolumn{7}{|l|}{ Doses } \\
\hline $0 \mathrm{~N}$ & $59,4 \mathrm{c}$ & $106 \mathrm{~d}$ & $10,3 \mathrm{c}$ & $23,3 \mathrm{c}$ & 1450 c & $119,5 \mathrm{c}$ \\
\hline $25 \mathrm{~N}$ & $72,7 \mathrm{~b}$ & $121 \mathrm{c}$ & $11,9 \mathrm{~b}$ & $23,6 \mathrm{~b}$ & $1957 \mathrm{~b}$ & $169,0 \mathrm{~b}$ \\
\hline $50 \mathrm{~N}$ & 78,6 a & $125 \mathrm{~b}$ & $11,4 \mathrm{~b}$ & $23,8 \mathrm{a}$ & 2106 a & $184,5 \mathrm{a}$ \\
\hline $75 \mathrm{~N}$ & 81,0 a & 128 a & $13,0 \mathrm{a}$ & $23,6 \mathrm{~b}$ & 2118 a & 187,5 a \\
\hline C.V. $(\%)$ & 7,42 & 2,68 & 8,13 & 1,11 & 3,29 & 8,43 \\
\hline
\end{tabular}

Obs. Médias seguidas de mesma letra, na coluna, não diferem entre si ao nível de $5 \%$ pelo teste de Tukey.

Quadro 5. Componentes de renda e rendimento do arroz de terras altas, em sucessão ao feijoeiro, em função de adubos verdes e adubação nitrogenada. Jaboticabal (SP), 2000

\begin{tabular}{|c|c|c|c|}
\hline Adubos verdes & Renda sem casca & Renda beneficiado & Renda de grãos inteiros \\
\hline & & $\%$ & \\
\hline Testemunha "no limpo" & $80,1 \mathrm{~b}$ & $69,9 \mathrm{c}$ & $40,4 \mathrm{c}$ \\
\hline Canavalia brasiliensis & $80,1 \mathrm{~b}$ & $70,0 \mathrm{c}$ & $41,4 \mathrm{~b}$ \\
\hline Crotalaria juncea cv. IAC-KR1 & $80,2 \mathrm{~b}$ & $70,7 \mathrm{ab}$ & 39,0 e \\
\hline Pennisetum glaucum cv. BN-2 & $80,6 \mathrm{ab}$ & $70,1 \mathrm{c}$ & $42,1 \mathrm{ab}$ \\
\hline Sorghum bicolor cv. AG-2501C & 80,8 a & $70,4 \mathrm{bc}$ & $39,6 \mathrm{~d}$ \\
\hline Sorghum bicolor tipo guinea & $80,5 \mathrm{ab}$ & 70,9 a & $42,2 \mathrm{a}$ \\
\hline C.V. $(\%)$ & 0,55 & 0,58 & 1,37 \\
\hline \multicolumn{4}{|l|}{ Doses } \\
\hline $0 \mathrm{~N}$ & $79,9 \mathrm{~b}$ & $70,1 \mathrm{bc}$ & $40,2 \mathrm{~b}$ \\
\hline $25 \mathrm{~N}$ & $79,8 \mathrm{~b}$ & $70,0 \mathrm{c}$ & $41,2 \mathrm{a}$ \\
\hline $50 \mathrm{~N}$ & 80,9 a & $70,4 \mathrm{ab}$ & $40,6 \mathrm{ab}$ \\
\hline $75 \mathrm{~N}$ & 80,9 a & $70,8 \mathrm{a}$ & $41,0 \mathrm{a}$ \\
\hline C.V. $(\%)$ & 0,56 & 0,69 & 1,75 \\
\hline
\end{tabular}

Obs. Médias seguidas de mesma letra, na coluna, não diferem entre si ao nível de $5 \%$ pelo teste de Tukey. 
Na Figura 3b pode-se observar um aumento quadrático na produtividade de proteína bruta com o aumento da dose de $\mathrm{N}$ em cobertura e, ainda, um acréscimo significativo mesmo na ausência de adubação nitrogenada, proporcionada pelas leguminosas e pelo milheto, quando comparado ao tratamento "no limpo".

BARBOSA FilHo (1987) ressalta que a adubação nitrogenada, além de influenciar positivamente os componentes da produção e produtividade, também proporciona acréscimo no teor de proteína nos grãos de arroz. De Datta et al. (1972), Gomes e De Datta (1975) e Vieira e CARVAlHo (1999) afirmam que o conteúdo protéico de grãos do arroz pode sofrer interferência pelo tipo e quantidade de fertilizantes nitrogenado aplicado, fatores climáticos, controle fitossanitário adequado, características varietais, maturação dos grãos e pelo grau de polimento do grão no beneficiamento.

Barbosa Filho e Fonseca (1994) citam a existência de correlação inversa entre teor de proteína e produtividade em arroz irrigado. Consideram que o efeito do nitrogênio não deve ser analisado isoladamente, pois outros fatores, como genótipo, tamanho do grão, produtividade de grãos, teor de umidade dos grãos no momento da colheita, entre outros, podem afetar o teor protéico dos grãos de arroz.

Com relação ao número de panículas por área $\left(\mathrm{m}^{2}\right)$, verificou-se que o aumento proporcionado pela adubação nitrogenada foi ainda maior, quando o cultivo do arroz foi realizado após leguminosas / feijoeiro (Quadro 4 e Figura 3 c). STONE et al. (1999), trabalhando com doses entre 0 e $160 \mathrm{~kg} \cdot \mathrm{ha}^{-1}$ de $\mathrm{N}$ na cultura de arroz de terras altas, encontraram resposta quadrática para número de panículas por metro quadrado, com valor máximo atingido na dose de $130,8 \mathrm{~kg} \cdot \mathrm{ha}^{-1}$.

Entretanto, para essa última característica no presente experimento, observou-se o menor valor sem o cultivo anterior de adubos verdes, ou seja "no limpo", mesmo em sucessão ao feijoeiro (Quadro 4).

Houve também aumento da massa de 1.000 grãos quando se incrementaram as doses de nitrogênio (Figura 3d). De modo geral, quando a cultura do arroz sucedeu a seqüência $C$. juncea / feijoeiro foram observados aumentos nos componentes produtivos.

O quadro 5 apresenta os valores referentes à renda sem casca, renda de benefício e renda de grãos inteiros. Obteve-se aumento na renda de arroz sem casca e renda de benefício com a aplicação das maiores doses de $\mathrm{N}$ em cobertura. Embora tenha ocorrido diferença significativa entre os adubos verdes, para os valores de renda, pode-se verificar que a diferença entre o maior e o menor valor, obtidos com adubo verde, foi de $0,7 \%$ para renda sem casca e de $1 \%$ para renda de beneficiamento, valores considerados baixos do ponto de vista agrícola. As médias de rendimento de grãos inteiros estão próximas daquelas obtidas por ARF et al. (2000) no primeiro ano de experimento sobre desempenho de cultivares de arroz de sequeiro em diferentes épocas de semeadura. Segundo os autores, fatores climáticos como distribuição de chuvas podem interferir nesses resultados.

\section{CONCLUSÕES}

1. O cultivo dos adubos verdes $C$. juncea, $C$. brasiliensis, P. glaucum, sorgo AG-2501C e Sorghum bicolor tipo guinea, semeados até 10 de março, é agronomicamente viável, com produção de matéria seca acima de 6,0 t.ha ${ }^{-1}$ para as leguminosas e acima de 9,5 t.ha ${ }^{-1}$ para gramíneas.

2. Na ausência de adubação nitrogenada, mas em sucessão à $C$. juncea e $C$. brasiliensis são obtidas produtividades superiores a $1.990 \mathrm{~kg} \cdot \mathrm{ha}^{-1}$ de feijão.

3. Sucedendo-se às leguminosas são proporcionadas maiores produtividades de feijão, com menores doses exigidas de adubação nitrogenada.

4. As maiores produtividades de arroz de terras altas foram obtidas nos tratamentos com leguminosas/feijoeiro e milheto/feijoeiro. A produtividade máxima estimada de $3.044 \mathrm{~kg} \cdot \mathrm{ha}^{-1}$ seria alcançada com $80 \mathrm{~kg} \cdot \mathrm{ha}^{-1}$ de $\mathrm{N}$ para C. juncea.

5. A utilização dos sorgos AG-2501C e guiné ocasionaram diminuição dos componentes da produção e da produtividade de arroz.

\section{AGRADECIMENTOS}

À Fundação de Amparo à Pesquisa do Estado de São Paulo (FAPESP), pela bolsa de iniciação científica concedida para a realização deste trabalho.

Aos funcionários do Departamento de Produção Vegetal e da FCAV, pela instalação e manejo do experimento durante o período de março de 2000 a abril de 2001.

\section{REFERÊNCIAS BIBIOGRÁFICAS}

ALVARENGA, R.C.; CABEZAS, W.A.L.; CRUZ, J.C.; SANTANA, D.P.; Plantas de cobertura de solo para sistema de plantio direto. Informe Agropecuário, Belo Horizonte, v.22, n.208, p.25-36, 2001. 
AMBROSANO, E.J.; WUTKE, E.B.; BULISANI, E.A.; CANTARELLA, H.. In: Feijão. In: RAIJ, B.van.; CANTARELLA, H.; QUAGGIO, J.A.; FURLANI, A.M.C. Recomendações de adubação e calagem para o Estado de São Paulo. 2.ed. Campinas: IAC, 1997. p.194-195. (Boletim Técnico 100).

ARF, O.; RODRIGUES, R.A.; CRUSCIOL, C.A.C; SÁ, M.E.; BUZETTI, S. Soil management and nitrogen fertilization for sprinkler-irrigated upland rice cultivars. Scientia Agrícola, Piracicaba, v.60, n.2, p.345-35, 2003.

ARF, O.; RODRIGUES, R.A.F.; SÁ, M.E.; CRUSCIOL, C.A.C. Influência da época de semeadura no comportamento de cultivares de arroz irrigado por aspersão em Selvíria, MS. Pesquisa Agropecuária Brasileira, Brasília, v.35, n.10, p.1967-1976, 2000

ARF, O.; SILVA, L.S. da; BUZETTI, S.; ALVES, M.C.; SÁ, M.E. de; RODRIGUES, R.A.; HERNANDEZ, F.B.T. Efeito da rotação de culturas, adubação verde e nitrogenada sobre o rendimento do feijão. Pesquisa Agropecuária Brasileira, Brasília, v.34, n.11, p.2029-2036, 1999.

BARBOSA FILHO, M. P.; FONSECA, J. R. Importância da adubação na qualidade do arroz. In: SÁ, M.E.; BUZZETI, S. (Coords.). Importância da adubação na qualidade dos produtos agrícolas. São Paulo: Ícone, 1994. p. 217-31.

BARBOSA FILHO, M.P. Nutrição e adubação do arroz: sequeiro e irrigado. Piracicaba: Potafós, 1987. 129 p. (Boletim Técnico 9).

CANTARELLA, H.; FURLANI, P.R. Arroz de sequeiro. In: RAIJ, B.van.; CANTARELLA, H.; QUAGGIO, J.A.; FURLANI, A.M.C. Recomendações de adubação e calagem para o Estado de São Paulo. 2.ed. Campinas: IAC, 1997. p.48-49. (Boletim Técnico 100).

CARVALHO, M.A.C.. Adubação verde e sucessão de culturas em semeadura direta e convencional em Selvíria-MS. 2000. 189f. Tese (Doutorado) - Faculdade de Ciências Agrárias e Veterinárias, Universidade Estadual Paulista, Jaboticabal.

CASTRO FILHO, C.; CORSINI, P. C.; SOARES, D.; POLITANO, $\mathrm{W}$. Acceptance of soil and water conservation: strategies and technologies in southern Brazil. In: BAUM, E.; WOLF, P., ZOBISCH, M. A. (Eds.). Topics in applied resource management in the tropics: acceptance of soil and water conservation, strategies and technologies. Witzenhaussen: German Institute for Tropical and Subtropical Agriculture, 1993. v.3, p.341-361.

CRUZ, J.C.; PEREIRA FILHO, I.A.; ALVARENGA, R.C.; SANTANA, D.P. Plantio direto e sustentabilidade agrícola. Informe Agropecuário, Belo Horizonte, v.22, n.208, p.13-24, 2001.

DE DATTA, S.K.; OBCEMA, W.N.; JANA, R.K. Protein content of rice grains as affected by nitrogen fertilizer and some triazines and substituted ureas. Agronomy Journal, Madison, v.64, p.785-788, 1972.

DERPSCH, R.; SIDIRAS, N.; HEINZMANN, F. X. Manejo do solo com coberturas verdes de inverno. Pesquisa Agropecuária Brasileira, Brasília, v.20, n.7, p.761-73, 1985.

DINIZ, A.R. Resposta da cultura do feijão (Phaseolus vulgaris L.) à aplicação de nitrogênio (semeadura e cobertura) e de molibdênio foliar. 1995. 60f. Dissertação (Mestrado) - Universidade Federal de Lavras.
EMBRAPA. Centro Nacional de Pesquisa de Solos. Sistema brasileiro de classificação de solos. Rio de Janeiro: Embrapa: CNPS, 1999. 412p.

FORNASIERI FILHO, D. Efeitos do N, P, K, S e Zn no desenvolvimento, produção e composição mineral do arroz (Oryza sativa L.) cv. IAC 47 e IAC 435. 1982. 157f. Tese (Doutorado em Agronomia/Solos e Nutrição de Plantas)- Escola Superior de Agricultura "Luiz de Queiroz", Piracicaba.

GOMES, K.A.; DE DATTA, S.K. Influence of environment on protein content of rice. Agronomy Journal, Madison, v.67, p.565$568,1975$.

MARENCO, R.A.; SANTOS, A.M.B. Crop rotation reduces weed competition and increases chlorophyl concentration and yield of rice. Pesquisa Agropecuária Brasileira, Brasília, v.34, n.10, p.1881-1887, 1999.

PETERS, G.A.; CALVERT, H.F. The Azzola - Anabaena symbiosis. In: RAOS, N.S.S. (Eds.). Advances in agricultural microbiology. New Delhi: Oxford \& Igh, 1982. p191-218.

PRIMAVESI, O.; PRIMAVESI, A. C.; NOVAES, N. J. Minerais em adubos verdes conduzidos sobre latossolos na região de São Carlos, SP, Brasil. II -Extração por tonelada de matéria seca. In: REUNIÃO BRASILEIRA DE FERTILIDADE DO SOLO E NUTRIÇÃO DE PLANTAS, 22., Manaus, 1996. Resumos expandidos... Manaus: Universidade do Amazonas, 1996a. v.1, p.94-95.

PRIMAVESI, O.; PRIMAVESI, A. C.; NOVAES, N. J. Minerais em adubos verdes conduzidos sobre latossolos na região de São Carlos, SP, Brasil. II. Relação com a produção de matéria seca. In: REUNIÃO BRASILEIRA DE FERTILIDADE DO SOLO E NUTRIÇÃO DE PLANTAS, 22., Manaus, 1996. Resumos expandidos.... Manaus: Universidade do Amazonas, 1996b, v.1, p.92-93.

RAIJ, B. VAN. Análise química de solos para fins de fertilidade. Campinas: Fundação Cargill, 1987. 170p.

SARRUGE, J.R.; HAAG, H.P. Análises químicas em plantas. Piracicaba: Escola Superior de Agricultura Luiz de Queiroz, 1974. 56p.

SÉGUY, L.; BOUZINAC, S. Petit guide de gestion des couvertures pour lês systemes de culture macanisés em semis direct dans lês regions tropicales chaudes et humides de basse altitide du Centreouest brésilien. Montpellier: CIRAD-CA., 1996. 80p. (Doc. Interne).

SÉGUY, L.; BOUZINAC, S.; MARONEZZI, A.C.; TAFFAREL, V.; TAFFAREL, J. Plantio direto do arroz de sequeiro de alta tecnologia na zona tropical úmida do centro-norte do Mato Grosso. Piracicaba: POTAFOS, 1999. 29p. (POTAFOS: Encarte Técnico, 86).

STONE, L.F.; SANTOS, A.B.; STENMETZ, S. Influência de práticas culturais na capacidade de retenção de água do solo e no rendimento do arroz de sequeiro. Pesquisa Agropecuária Brasileira, Brasília, v.15, n.1, p.63-68, 1980.

STONE, L.F.; SILVEIRA, P.M.; MOREIRA, J.A.A.; YOKOYAMA, L.P. Adubação nitrogenada em arroz sob irrigação suplementar por aspersão. Pesquisa Agropecuária Brasileira, Brasília, v.34, n.6, p.927-932, 1999. 
VIEIRA, N.R.A.; CARVALHO, J.L.V. Qualidade tecnológica. In: VIEIRA, N.R.A.; SANTOS, A.B.; SANT'ANA, E.P. (Coord.). A cultura do arroz no Brasil. Santo Antonio de Goiás: Embrapa Arroz e Feijão, 1999. p.582-604.
WUTKE, E. B.; FANCELLI, A. L.; PEREIRA, J. C. V. N. A. ; AMBROSANO , G. M. B. Rendimento do feijoeiro irrigado em rotação com culturas graníferas e adubos verdes. Bragantia, Campinas, v. 57, n.2, p. 325-338, 1998. 